\title{
Pemanfaatan Internet sebagai Media Pemasaran Pondok Wisata di Desa Pelaga, Kabupaten Badung
}

\author{
Ni Made Suastini1* ${ }^{*}$ I Gusti Agung Gede Witarsana², I Wayan Jata ${ }^{3}$, NLK Sri Sulistyawati ${ }^{4}, \mathrm{Ni}^{2}$ \\ Nyoman Sukerti ${ }^{5}$, Ni Luh Gde Sri Sadjuni6 \\ 1*2,3,4,5,6Program Studi Administrasi Perhotelan, Jurusan Hospitaliti, Politeknik Pariwisata Bali \\ Jalan Dharmawangsa, Kampial, Kel. Benoa, Kec. Kuta Selatan, Badung, Bali \\ 1*madesuastini@ppb.ac.id, 2agung.witarsana@ppb.ac.id,3yanjat@yahoo.com, \\ ${ }^{4}$ sulistyawati@ppb.ac.id, ${ }^{5}$ sukerti@ppb.ac.id, ${ }^{6}$ sriesad@ppb.ac.id \\ * Penulis Korespondesi
}

\begin{tabular}{l|l|l} 
Received: September,2021 & Accepted: November,2021 & Published: December, 2021
\end{tabular}

\begin{abstract}
Pelaga Village, Badung Regency is famous for its beautiful and natural view. Therefore, the community is very enthusiastic to manage homestay as a means of support. In Pelaga Tourism Village, agro-tourism development has also been carried out centered in the Kiadan environment. However, when the field survey was carried out, there were still obstacles in its management of the homestay. Therefore, training related to accommodation management is needed which will be carried out in stages to improve the community's ability to manage homestay. In 2021, the Hotel Administration Study Program has carried out community service in Pelaga Village, Badung Regency regarding the use of the internet as a marketing tools for homestay in Pelaga Village, Badung Regency.
\end{abstract}

Keywords: internet, homestay, marketing

\begin{abstract}
Abstrak
Desa Pelaga, Kabupaten Badung dikenal akan daya tarik alamnya yang indah dan sejuk. Oleh karena itu, masyarakat sangat antusias untuk mengelola pondok wisata sebagai sarana penunjang. Di Desa Wisata Pelaga juga sudah terdapat pengembangan agrowisata yang dipusatkan di lingkungan Kiadan. Namun, saat dilakukan penjajagan kegiatan pengabdian kepada masyarakat masih ditemui kendala-kendala dalam pengelolaannya. Oleh karena itu, dibutuhkan pelatihan terkait pengelolaan akomodasi yang akan dilakukan secara bertahap sehingga dapat meningkatkan kemampuan masyarakat dalam mengelola pondok wisata. Tahun 2021 ini Program Studi Administrasi Perhotelan melakukan pengabdian kepada masyarakat di Desa Pelaga, Kabupaten Badung yang berkaitan dengan pemanfaatan internet sebagai media pemasaran pondok wisata di Desa Pelaga, Kabupaten Badung.
\end{abstract}

Kata kunci: internet, pemasaran, pondok wisata 


\section{PENDAHULUAN}

Pada bulan Oktober Tahun 2020, Program Studi Administrasi Perhotelan (ADH) Politeknik Pariwisata Bali melaksanakan kegiatan Pengabdian kepada Masyarakat (PkM) di Desa Pelaga, Kabupaten Badung. Lingkup kegiatan tersebut adalah pengelolaan pondok wisata khususnya dalam memberikan pelayanan secara operasional (Food \& Beverage Product, Food \& Beverage Service, Front Office serta Housekeeping). Pada tahun 2021 ini, Program Studi Administrasi Perhotelan akan melanjutkan program kegiatan Pengabdian kepada Masyarakat di Desa Pelaga, Kabupaten Badung ini. Hal ini untuk memaksimalkan pengelolaan pondok wisata di Desa Pelaga, yaitu dengan memberikan pelatihan pemasaran pondok wisata melalui internet.

Adanya penerapan aturan baru pada era new normal dan Pembatasan Sosial Berskala Besar (PSBB), maka salah satu media dalam melakukan pemasaran untuk meningkatkan tingkat hunian kamar yaitu dengan memanfaatkan digitalisasi salah satunya website. Website merupakan media informasi dalam internet yang berguna baik untuk mempublikasikan sesuatu, mempromosikan ataupun mengunggah informasi yang penting. Penggunaan website dalam kegiatan promosi dapat membantu penghematan pengeluaran biaya promosi karena segala bentuk promosi dapat dipindahkan ke halaman pada website. Selain menghemat pengeluaran, pengoperasian website dapat dilakukan di rumah atau work from home (WFH) dimana dapat mengurangi angka kasus penularan pandemi Covid-19 di Bali. Bagi calon konsumen, website memberikan kemudahan dari sisi user experience dan penyampaian informasi yang cepat, tepat dan akurat.

Di era digitalisasi dan pandemi Covid-19, pemanfaatan website dalam mempromosikan produk dan jasa sangat penting sehingga pemilik pondok wisata harus mampu memahami bagaimana proses pengoperasian website. Dalam praktek lapangannya, beberapa pengelola pondok wisata kurang berinisiatif untuk bekerja sama dengan website pemesanan kamar karena pelaksanaan manajemen yang masih bersifat konvensional dan hanya mengandalkan pada tamu walk-in dengan kata lain pengelola pondok wisata belum mampu mengoptimalkan pemanfaatan website sebagai sarana promosi produk dan jasa dibandingkan akomodasi lainnya seperti hotel berbintang. Berdasarkan Statistik Hotel dan Akomodasi lainnya di Indonesia 2019, persentase akomodasi non bintang dan lainnya yang menggunakan internet sebagai media promosi di Provinsi Bali sebesar 75,97\% dari total 3.912 akomodasi non bintang dan lainnya.

Cara baru yang dapat digunakan sebagai alat pemasaran saat ini adalah pemasaran digital atau yang populer dikenal dengan digital marketing. pemasaran digital adalah suatu usaha pencapaian tujuan pemasaran melalui penggunaan teknologi digital (Chaffey \& Chadwick, 2012, p. 10). Sedangkan, Sanjaya dan Tarigan (2009:47) menyatakan pemasaran digital juga diartikan sebagai aplikasi internet dan teknologi digital yang berkaitan dengan pemasaran tradisional untuk mencapai tujuan pemasaran. Pada dasarnya pemasaran digital adalah sebuah kegiatan pemasaran melalui dunia digital sehingga dapat menjangkau target pasar yang lebih luas, sehingga dapat mencapai suatu tujuan pemasaran.

Promosi secara elektronik (electronic promotions) dapat dilakukan melalui internet. Usaha akomodasi memiliki data pelanggan (customers database) yang dikumpulkan saat proses reservasi dan registrasi. Usaha akomodasi yang 
mengelola database-nya dengan baik dapat memiliki puluhan ribu pelanggan dan hal ini adalah potensi yang dapat dimanfaatkan untuk meningkatkan pendapatan. Informasi tentang produk baru dan program promosi khusus dapat dilakukan direct mails melalui pengiriman e-news letter kepada pelanggan.

Pemanfaatan website harus mampu berorientasi kepada calon konsumen sehingga memiliki daya tarik yang mampu memikat calon konsumen untuk mengunjungi website tersebut. Salah satu daya tarik yang diberikan oleh homestay di Desa Pelaga adalah agrowisata yang lengkap dengan ekologinya yang indah. Di Desa Wisata Pelaga juga sudah terdapat pengembangan agrowisata yang dipusatkan di lingkungan Kiadan dengan potensi subak abiannya. Demikian pula terdapat agrowisata di lingkungan Auman dengan ciri khasnya terdapat terowongan air tradisional yang sudah menjadi daya tarik wisata. Terowongan air tersebut merupakan local genious masyarakat lokal yang dulu bisa membangun terowongan air tanpa mempergunakan teknologi, tetapi hanya dengan mempergunakan peralatan tradisional. Di Desa Wisata Pelaga juga terdapat Pura Pucak Mangu yang merupakan Pura Khayangan Jagat dengan memiliki nilai yang sangat sakral. Pucak Mangu inilah dijadikan inspirasi sebagai Ibukota Kabupaten Badung yang sekarang bernama Mangu Pura. Dengan berbagai daya tarik yang dimiliki Desa Pelaga tersebut perlu mendapat dukungan pemerintah, sesuai dengan hasil penelitian dari Sari et al. (2020) bahwa peranan pemerintah lokal dan regional sebagai faktor eksternal memiliki peran penting dalam pengembangan agrowisata di Desa Pelaga Kecamatan Petang. Pemerintah lokal dan regional mampu menyediakan berbagai fasilitas dan infrastruktur, sekaligus membuat regulator untuk mengembangkan agrowisata setempat.

Keberadaan Pondok Wisata di Desa Pelaga tersebar di 7 dari 9 banjar yang ada di Desa tersebut yakni Banjar Pelaga, Banjar Bukian, Banjar Kiadan, Banjar Nung-Nung, Banjar Auman, Banjar Bukit Munduktiying dan Banjar Tiyingan. Jumlah Pondok wisata yang ada di Desa Pelaga dapat dilihat pada Tabel 1.

Tabel 1. Pondok Wisata di Desa Pelaga

\begin{tabular}{|c|c|c|c|}
\hline NO & BANJAR & NAMA PONDOK WISATA & JUMLAH KAMAR \\
\hline 1. & Br. Pelaga & Pondok Agro Homestay & 3 kamar \\
\hline 2. & Br. Kiadan & Pondok Wana & 5 kamar \\
\hline 3. & Br. Kiadan & Pondok Warsa & 3 kamar \\
\hline 4. & Br. Nungnung & Pondok Jaka & 1 kamar \\
\hline 5. & Br. Auman & Pondok Wisata Bejalin & 5 kamar \\
\hline 6. & Br. Auman & Pondok Wisata Bali Treek & 4 kamar \\
\hline 7. & Br. Bukit Munduktiying & Pondok Wisata Pelaga & 2 kamar \\
\hline 8. & Br. Bukit Munduktiying & Pondok Wisata Bukit Bali & 3 kamar \\
\hline 9. & Br. Bukian & I Made Supariyasa & 3 kamar \\
\hline 10. & Br. Bukian & I Nyoman Sadra & 4 kamar \\
\hline 11. & Br. Bukian & I Wayan Gim & 2 kamar \\
\hline 12. & Br. Bukian & I Wayan Yuda & 2 kamar \\
\hline 13. & Br. Tiyingan & Homestay A & 3 kamar \\
\hline 14. & Br. Tiyingan & Homestay B & 5 kamar \\
\hline & Jumlah & 14 Pondok Wisata & 45 kamar \\
\hline
\end{tabular}

[Sumber: Laporan PkM Prodi ADH , 2020]

Pada Tabel 1 dapat dilihat jika keberadaan Pondok Wisata di Desa Pelaga terdapat 14 Pondok Wisata yang terdiri dari 45 kamar, berdasarkan jumlah tersebut maka 
dapat disimpulkan jika keberadaan Pondok Wisata di Desa Pelaga terbilang cukup banyak. Namun, saat dilakukan penjajagan kegiatan pengabdian kepada masyarakat di tahun 2020 masih ditemui kendala-kendala dalam pengelolaannya. Selain itu, berdasarkan pengamatan yang telah dilakukan di beberapa pondok wisata bahwa masih banyak pondok wisata yang belum memiliki kemampuan dalam melakukan pemasaran pondok wisatanya melalui internet. Rata-rata pengelola pondok wisata juga belum memiliki kemampuan terkait pemanfaatan media sosial sebagai upaya menarik keinginan wisatawan untuk menginap. Jumlah tamu yang menginap terhitung sedikit. Bahkan dalam kurun waktu satu bulan, bisa tidak ada tamu yang menginap. Menurut Suprastayasa et al. (2020) pentingnya peranan sumber daya manusia dalam pengembangan desa wisata dan juga agar masyarakat lokal dapat memperoleh manfaat dari pengembangan desa wisata maka peningkatan kapasitas masyarakat lokal penting untuk terus menerus dilakukan. Oleh karena itu, tahun lalu Program Studi Administrasi Perhotelan telah melakukan pelatihan operasional seperti $F \& B$ Service, F \& B Product dan Front Office untuk meningkatkan kapasitas pengelola pondok wisata di bidang akomodasi. Selanjutnya di Tahun 2021 ini dilakukan pelatihan yang berkaitan dengan pemasaran pondok wisata melalui internet. Hal ini sesuai dengan pendapat dari Mujiyana dan Elissa (2013) yang mengungkapkan bahwa edukasi pengelolaan dalam pasar online adalah penting agar produk dikenal masyarakat luar daerah, konten digital terutama promosi melalui internet sangat berpengaruh terhadap keputusan konsumen dalam membeli produk secara daring.

\section{METODE PELAKSANAAN KEGIATAN}

Pelatihan Pemanfaatan Internet sebagai Media Pemasaran Pondok Wisata di Desa Petang, Kabupaten Badung ini dilaksanakan melalui tiga tahap, yaitu perencanaan, pelaksanaan dan pelaporan. Pada tahap perencanaan dilakukan penjajagan ke lapangan untuk mendapatkan data dan informasi terkait kondisi dan situasi Pondok Wisata di Desa Petang, Kabupaten Badung. Tahap pelaksanaan yaitu dilaksanakannya pelatihan pemanfaatan internet sebagai media pemasaran pondok wisata yang berlokasi di Bagus Agro, Desa Pelaga Kabupaten Badung dalam bentuk ceramah dan praktek pendampingan kepada peserta (pemilik/pengelola pondok wisata) yang berjumlah 30 orang. Metode ceramah dilakukan dengan menyampaikan pentingnya digitalisasi dalam memasarkan pondok wisata serta kendala-kendala yang dihadapi oleh peserta dalam memasarkan pondok wisatanya. Sedangkan praktek pendampingan dilakukan dengan memberikan kesempatan kepada peserta untuk mengetahui alur penggunaan website dengan praktek langsung dengan menggunakan handphone maupun laptop. Sedangkan tahap pelaporan yaitu dilakukan evaluasi terhadap seluruh kegiatan yang telah dilakukan.

\section{HASIL DAN PEMBAHASAN}

Hasil yang dicapai dari kegiatan pengabdian kepada masyarakat yang dilaksanakan di Desa Pelaga, Kabupaten Badung oleh Program Studi Administrasi Perhotelan antara lain adalah peserta memiliki pengetahuan sesuai dengan kemajuan teknologi sehingga produktivitas dapat ditingkatkan dengan cara-cara 
yang efektif dan efisien salah satunya dengan memanfaatkan internet dan peserta pelatihan mampu untuk mempraktekkan bagaimana melakukan reservasi melalui website dalam pemesanan kamar di pondok wisata.

Peserta sangat antusias untuk mengikuti pelatihan ini, namun karena memperhatikan protokol kesehatan dan dapat memenuhi kriteria physical distancing maka jumlah peserta dibatasi 30 orang. Untuk meningkatkan kualitas pelaksanaan pengabdian kepada masyarakat di waktu selanjutnya, dilakukan evaluasi dengan menyebarkan kuesioner kepada peserta dengan hasil seperti pada Tabel 2. Kuesioner terdiri dari 4 dimensi dengan 18 indikator dimana terdapat 4 pilihan jawaban yaitu sangat setuju, setuju, tidak setuju dan sangat tidak setuju.

Tabel 2. Hasil Penilaian Peserta

\begin{tabular}{clrc}
\hline No & \multicolumn{1}{c}{ Indikator } & Nilai & Kategori \\
\hline A & NARASUMBER & 3,6 & Sangat Setuju \\
1 & Metode kelatihan menarik & 3,7 & Sangat Setuju \\
2 & Narasumber menguasai materi & 3,6 & Sangat Setuju \\
3 & Komunikatif & 3,5 & Sangat Setuju \\
4 & Presentasi menarik & 3,6 & Sangat Setuju \\
5 & Memberi kesempatan untuk diskusi / bertanya & & \\
B & MATERI PELATIHAN & 3,8 & Sangat Setuju \\
6 & Sasaran/tujuan pelatihan jelas & 3,5 & Sangat Setuju \\
7 & Relevan dengan kebutuhan peserta pelatihan & 3,6 & Sangat Setuju \\
8 & Bermanfaat untuk peserta pelatihan & 3,5 & Sangat Setuju \\
9 & Cakupan materi memadai & & Sangat Setuju \\
10 & Materi pelatihan sesuai dengan perkembangan di & 3,6 & \\
& industri & & \\
C & SUASANA & 3,4 & Sangat Setuju \\
11 & Tepat waktu & 3,4 & Sangat Setuju \\
12 & Peserta pelatihan aktif & 3,8 & Sangat Setuju \\
13 & Rehat snack dan makan siang memadai & 3,7 & Sangat Setuju \\
14 & Panitia bekerja dengan baik & 3,7 & Sangat Setuju \\
15 & Pelatihan tidak membosankan & & \\
D & SARANA/PRASARANA & 3,7 & Sangat Setuju \\
16 & Tempat pelaksanaan pelatihan memadai & 3,7 & Sangat Setuju \\
17 & Fasilitas praktek dalam pelatihan lengkap & 3,7 & Sangat Setuju \\
18 & Fasilitas audiovisual lengkap & $\mathbf{3 , 6 2}$ & Sangat Setuju \\
\hline & Penilaian secara keseluruhan & &
\end{tabular}

[Sumber : Kuesioner, data diolah tahun 2021]

Penetapan kategori dengan menggunakan interval kelas dengan klasifikasi sebagai berikut :

Sangat Tidak Setuju : 1,00 - $<1,75$

Tidak Setuju $\quad: 1,75-<2,50$

Setuju $\quad: 2,50-<3,25$

Sangat Setuju $\quad: 3,25-4,00$

Merujuk pada Tabel. 2, dapat dilihat bahwa semua indikator memperoleh penilaian yang termasuk kategori Sangat Setuju dengan nilai rata-rata sebesar 3,62. Hal tersebut berarti bahwa Narasumber/Fasilitator, Materi Pelatihan, Suasana serta Sarana/Prasarana dinilai Sangat Baik oleh para peserta. Penilaian tertinggi diberikan untuk indikator "Sasaran dan tujuan pelatihan jelas" dengan 
nilai 3,80. Sedangkan indikator yang memperoleh penilaian paling rendah adalah "tepat waktu" dan "peserta pelatihan aktif" dengan nilai 3,40. Hal tersebut kemungkinan besar disebabkan karena adanya penyesuaian waktu pada saat pemaparan materi oleh narasumber yang hampir melebihi waktu serta beberapa peserta masih malu-malu dalam menyampaikan pendapat karena kurang percaya diri.

\section{KESIMPULAN}

Pengabdian kepada masyarakat Program Studi Administrasi Perhotelan yang dilaksanakan di Bagus Agro, Desa Pelaga Kabupaten Badung telah terlaksana dengan baik dan memperoleh penilaian yang sangat baik dari peserta yang diperoleh dari hasil kuesioner.

Kegiatan pengabdian kepada masyarakat yang dilakukan ini sangat bermanfaat dalam meningkatkan pengetahuan peserta dalam memanfaatkan media online sebagai sarana pemasaran pondok wisata, sehingga memberikan peluang untuk memperluas market yang selanjutnya diharapkan dapat meningkatkan tingkat hunian kamar pondok wisata. Pengabdian kepada masyarakat untuk pengelola pondok wisata berupa pelatihan pemanfaatan internet sebagai media pemasaran pondok wisata sangat perlu karena perkembangan digitalisasi yang menuntut para pelaku usaha untuk bersaing secara global dengan sistem pemasaran online.

\section{DAFTAR PUSTAKA}

Chaffey, D., \& Ellis-Chadwick, F. (2012). Digital Marketing Strategy, Implementation and Practice. Fifth Edition, Pearson.

Mujiyana, M. \& Elissa, I. (2013). Analisis Faktor-Faktor Yang Mempengaruhi Keputusan Pembelian Via Internet Pada Toko Online. J@Ti Undip : Jurnal Teknik Industri, 8(3), pp. 143-152.

Sanjaya, R., \& Josua, T. (2009). Creative Digital Marketing. Jakarta: PT Elex Media Komputindo.

Sari, T., Selamet, K., \& Purnami, S. (2020). Analisis SWOT Dalam Pengembangan Agrowisata di Desa Pelaga Kecamatan Petang Kabupaten Badung. Wacana Ekonomi Uurnal Ekonomi, Bisnis dan Akuntansi), 19(1), pp.1-9. http://dx.doi.org/10.22225/we.19.1.1575.1-9.

Suprastayasa, I.G.N.A., Adi, I.A.S.P. \& Iswarini, N. K. (2020). Pelatihan Merangkai Bunga Bagi Masyarakat Desa Wisata Gunung Salak, Tabanan, Bali. Jurnal Pemberdayaan Pariwisata, [S.I.], 2, (2), p. 111-116. ISSN 2715-9078. 